\title{
TESTING THE PERFORMANCE OF PROBABILITY FUNCTIONS WITH LONG TERM DATA OF EXTREME RAINFALL
}

\author{
Shreyas, H.C ${ }^{1}$, Mysooru R. Yadupathi Putty ${ }^{2}$ \\ ${ }^{1}$ Asst. Professor, Gopalan College of Engineering and Management, Bengaluru, Karnataka, India \\ ${ }^{2}$ Professor, The National Institute of Engineering, Mysuru, Karnataka, 570008 India
}

\begin{abstract}
Frequency analysis of data on flood and extreme rainfall, for estimation of the peak flood magnitude, is among the most commonly adopted design procedures in Hydrology. The best fitting among the different available Probability functions, selected based on analysis of recorded data of 30 - 40 years, is used in estimation of design values of different return periods like 50, 75 and 100 years. The present study has been carried out to test the performance of the 'best fitting' functions in estimating design values of extreme daily, 2- daily and 4-daily rainfall in the region of Western Ghats in Karnataka, for which rainfall records of over a century is available. The work has been carried out by analyzing 40 years' data from four stations, and by adopting the Normal, Log-Normal, the Gumbel and the Log-Gumbel distributions. Commonly used tests of goodness of fit have been used to select the best fitting function. Peak values of 50,75 and 100 years are estimated and compared with the observed values. The results are discussed and inferences drawn.
\end{abstract}

Keywords-Extreme events, Probability functions, Peak rainfall estimation, Reliability of prediction.

$* * *$

\section{INTRODUCTION}

One of the most important Engineering applications of Hydrology is the estimation of the Design peak flood, values of which are used in design of vent ways, and spillways. When data of flood magnitudes at the site where a structure is to be located is available, frequency analysis of extreme events is used for the purpose. Otherwise, design methodologies developed to estimate flood magnitude from peak rainfall intensities are used for the purpose. In either case, extreme values, most generally annual extremes, are subject to frequency analysis and theoretical distributions are used to extrapolate peak values of the desired return periods. Most commonly, data of 30 - 40 years are used to determine the best fitting theoretical distribution, which is then used to estimate peak values of the variable for return periods of the kind 50-, 75-, 100-, 200- years. The assumption that the theoretical distribution found to fit the available length of data, also fits the lengthier records, if they were available, forms the basis for the estimations done in Probability studies. Hence, there is a pinch of uncertainty involved in all predictions, however well the theoretical function fits the available data. Consequently, Confidence limits are attached to the point estimates and Reliability studies are also taken up as a part of Frequency studies. However, when lengthy records are available, it would be indeed interesting to understand the extent to which the probability functions perform well in extrapolating peak values. The present work has been taken up in order to understand this particular aspect pertaining to the estimation of peak daily and peak multidaily rainfall values, which are often used in estimation of design flood (Ellis and Gray, 1966; Williams, 1983; Putty and Dayananda, 1996). The Central Water Commission uses Peak 24 - hour rainfall values of estimation of Peak t-hour intensities (CWC, 1982, 1986, for example), which is in turn used in estimation of the peak flood. Since daily rainfall records pertaining to some stations in Karnataka are now available for lengths of over 100 years, it is possible to cross check the estimations done using shorter records. In the present study records of three stations in Karnataka Agumbe, Kottigehara and Ponnampete, situated in the Western Ghat areas, are used to study the reliability of the "best fitting" probability functions. Some details regarding these stations are presented in Table 1. The methodology used is explained below, and the results and discussions follow.

\section{METHODOLOGY}

The methodology used in this work can be summarized into a series of steps as below:

(1) A 40 year period of data is chosen for probability analysis from the available length of records;

(2) From the daily data, continuous records of 2-daily 3-daily and 4-daily values are created and the extreme values of these data for each year are obtained. Hence, for each set of data, a forty year length of extreme rainfall record is prepared. These records are subject to probability analysis.

(3) The statistical parameters required for fitting the chosen distributions by the Method of Moments are computed. In the present work the Log-Normal, Gumbel and Log-Gumbel distributions have been adopted. Hence, the parameters required to fit these distributions (Putty, 2010) are computed. The details are shown in Table 2.

(4) Actual probability of the data corresponding to the various years is computed using the Weibull Plotting Position formula, by arranging the set of data in descending order. Then, using the theoretical distributions, the corresponding theoretical values of the rainfall are computed. 
(5) The theoretical values of extreme rainfall estimated using the various distribution are compared with the observed rainfall values by the commonly used methods. In the present study, scatter diagrams and the test statistics of Coefficient of Efficiency (CE) and Kolmorgov - Smirnov (K-S) test are used. The best fitting function, selected based on the results of the tests, is then adopted for further work.

(6) Extreme values of recurrence interval 50- and 100-years are estimated using the selected function and tabulated for being compared with the corresponding actual values obtained from the complete length of the available records.

\section{RESULTS AND DISCUSSIONS}

A few scatter diagrams showing the values of extreme rainfall estimated by the various distributions plotted against the observed values are presented in Fig. 1. The values of the test statistics (CE and $\Delta$ for K-S test) are presented in Table 3 and Table 4, respectively. It is evident from these illustrations that all the three distributions fit well the data. However, relatively, the Log-Normal in the case of Agumbe and Log-Gumbal in the other two, are found to be the better performing. It is observed that even in the higher ranges of magnitude these two distributions perform well. Hence the two are chosen for extrapolation and further scrutiny.

The magnitude of rainfall corresponding to the return periods of 50- and 100- years estimated using the 'best fitting' distributions are presented, along with the observed in Table 5. It is evident from the information in Table 5 that in two of the three stations, where Log-Gumbel distribution is used, the estimated values are 30 to $40 \%$ higher than the observed magnitudes. The consequences are obvious - all the structures turn out to be over-designed and extremely safe. But, the question remains - is there justice in assuming the best fitting function to be the best always?

\section{REFERENCES}

[1] CWC (Central Water Commission, 1982). Flood estimation report for Krishna and Pennar basins (Subzone-3h). Hydrology (Small catchments) Directorate, New Delhi.

[2] CWC (Central Water Commission, 1986). Flood estimation report for Kaveri basin subzone-3(i). Hydrology (Small catchments) Directorate, New Delhi: 58 pp.

[3] Ellis, W.H. and Gray, D.M. (1966). Interrelationship between the peak instantaneous and average daily discharges of small prairie streams. Canadian Agricultural Engineering. Bell, F.C. (1998). Estimating designs floods from extreme rainfall. Hydrology papers, Colorado state university, U.S.A. Vol.No.29.

[4] Putty, R.Y (2010). Principles of Hydrology. I.K. International Publishing House Pvt. Ltd. New Delhi.

[5] Putty, R.Y. and Dayananda, S. (1996). Frequency Analysis of Extreme Rainfall for Estimation of Design Flood. J. Applied Hydrol., Vol.9, No. 3, 4, Page.No.32-39.
[6] Williams, W.S. (1983). Estimating peak discharges of small streams in Massachusetts. U.S. Ggeological survey water-supply paper 2214.

[7] G. Eason, B. Noble, and I.N. Sneddon, "On certain integrals of Lipschitz-Hankel type involving products of Bessel functions," Phil. Trans. Roy. Soc. London, vol. A247, pp. 529-551, April 1955. (references)

[8] J. Clerk Maxwell, A Treatise on Electricity and Magnetism, 3rd ed., vol. 2. Oxford: Clarendon, 1892, pp.68-73.

[9] I.S. Jacobs and C.P. Bean, "Fine particles, thin films and exchange anisotropy," in Magnetism, vol. III, G.T. Rado and H. Suhl, Eds. New York: Academic, 1963, pp. 271-350.

[10] K. Elissa, "Title of paper if known," unpublished.

[11] R. Nicole, "Title of paper with only first word capitalized," J. Name Stand. Abbrev., in press.

[12] Y. Yorozu, M. Hirano, K. Oka, and Y. Tagawa, "Electron spectroscopy studies on magneto-optical media and plastic substrate interface," IEEE Transl. J. Magn. Japan, vol. 2, pp. 740-741, August 1987 [Digests 9th Annual Conf. Magnetics Japan, p. 301, 1982].

[13] M. Young, The Technical Writer's Handbook. Mill Valley, CA: University Science, 1989. 
Table 1: Rain gauging stations selected for the study

\begin{tabular}{|l|l|l|l|l|l|}
\hline Station & District & Lat. & Long. & $\begin{array}{l}\text { Data used } \\
\text { for Pr. Anls. }\end{array}$ & Record length \\
\hline Kottigehara & Chikamagaluru & 1308 & 7536 & $1958-1997$ & $1898-1997$ \\
\hline Ponnampete & Kodagu & 1209 & 7556 & $1955-1994$ & $1898-1997$ \\
\hline Agumbe & Shivamogga & 1331 & 7506 & $1936-1975$ & $1898-1975$ \\
\hline
\end{tabular}

Table 2: Distribution parameters for the peak rainfall data chosen for Probability analysis.

\begin{tabular}{|c|c|c|c|c|c|c|c|c|c|c|c|c|c|}
\hline & & Daily & $\begin{array}{l}2- \\
\text { Daily }\end{array}$ & $\begin{array}{l}\text { 3- } \\
\text { Daily }\end{array}$ & $\begin{array}{l}\text { 4- } \\
\text { Daily }\end{array}$ & Daily & $\begin{array}{l}2- \\
\text { Daily }\end{array}$ & $\begin{array}{l}\text { 3- } \\
\text { Daily }\end{array}$ & $\begin{array}{l}\text { 4- } \\
\text { Daily }\end{array}$ & Daily & $\begin{array}{l}2- \\
\text { Daily }\end{array}$ & $\begin{array}{l}3- \\
\text { Daily }\end{array}$ & $\begin{array}{l}4- \\
\text { Daily }\end{array}$ \\
\hline \multirow{2}{*}{$\begin{array}{l}\text { Normal } \\
\text { Dist. }\end{array}$} & MEAN, & 312.1 & 522.8 & 693.5 & 284.6 & 489.0 & 655.4 & 799.7 & 194.8 & 307.1 & 391.4 & 446.7 & 836.6 \\
\hline & Stdev, & 80.3 & 123.4 & 168.5 & 140.3 & 238.3 & 314.1 & 394.0 & 116.9 & 183.7 & 229.4 & 253.9 & 199.2 \\
\hline \multirow{2}{*}{$\begin{array}{l}\text { LNor.- } \\
\text { Dist }\end{array}$} & $\mathrm{S}_{\mathrm{y}}$ & 0.253 & 0.233 & 0.239 & 0.466 & 0.461 & 0.454 & 0.466 & 0.554 & 0.553 & 0.543 & 0.529 & 0.23 \\
\hline & $\mu_{y}$ & 5.711 & 6.232 & 6.513 & 5.542 & 6.086 & 6.382 & 6.576 & 5.119 & 5.574 & 5.822 & 5.962 & 6.7 \\
\hline \multirow{2}{*}{$\begin{array}{l}\text { Gumb. } \\
\text { Dist }\end{array}$} & $\alpha$ & 62.6 & 96.2 & 131.4 & 109.4 & 185.8 & 245.0 & 307.3 & 91.1 & 143.3 & 178.9 & 198.0 & 155.4 \\
\hline & $\mathrm{a}$ & 275.9 & 467.2 & 617.7 & 221.4 & 381.7 & 513.9 & 622.3 & 142.2 & 224.4 & 288.1 & 332.4 & 746.9 \\
\hline \multirow{3}{*}{$\begin{array}{l}\text { LGum. } \\
\text { Dist }\end{array}$} & $\alpha_{y}$ & 0.20 & 0.18 & 0.19 & 0.36 & 0.36 & 0.35 & 0.36 & 0.43 & 0.43 & 0.42 & 0.41 & 0.18 \\
\hline & $\mathrm{a}_{\mathrm{y}}$ & 5.597 & 6.127 & 6.405 & 5.332 & 5.878 & 6.17 & 6.36 & 4.869 & 5.325 & 5.578 & 5.724 & 6.59 \\
\hline & SKEW & 1.37 & 0.33 & 0.26 & 2.2 & 2.2 & 1.7 & 1.7 & 2.1 & 2.0 & 2.0 & 1.9 & -0.12 \\
\hline
\end{tabular}

Table 3: Coefficient of Efficiency for estimation of rainfall magnitudes

\begin{tabular}{|l|l|l|l|l|l|l|l|l|l|l|l|l|}
\hline CE test & \multicolumn{4}{|l}{ Agumbe } & \multicolumn{4}{l|}{ Kottigehara } & \multicolumn{4}{|l|}{ Ponnampete } \\
\hline n- daily & Daily & $2-$ & $3-$ & $4-$ & $1-$ & $2-$ & $3-$ & $4-$ & $1-$ & $2-$ & $3-$ & $4-$ \\
\hline Log Norm. & 0.92 & 0.96 & 0.97 & 0.97 & 0.93 & 0.93 & 0.96 & 0.96 & 0.94 & 0.95 & 0.95 & 0.95 \\
\hline Gumbel & 0.93 & 0.95 & 0.97 & 0.94 & 0.90 & 0.90 & 0.94 & 0.94 & 0.90 & 0.92 & 0.91 & 0.92 \\
\hline Log Gumb. & 0.96 & 0.92 & 0.91 & 0.87 & 0.98 & 0.99 & 0.99 & 0.98 & 0.98 & 0.98 & 0.98 & 0.98 \\
\hline
\end{tabular}

Table 4: Values of Smirnov-Kolmorgov statistic (DEL) for various distributions.

\begin{tabular}{|c|c|c|c|c|c|c|c|c|c|c|c|c|}
\hline & \multicolumn{4}{|c|}{ Agumbe } & \multicolumn{4}{|c|}{ Kottigehara } & \multicolumn{4}{|c|}{ Ponnampete } \\
\hline & Daily & $2-$ & $3-$ & $4-$ & $1-$ & $2-$ & $3-$ & $4-$ & $1-$ & $2-$ & $3-$ & $4-$ \\
\hline Log Norm & 0.11 & 0.06 & 0.06 & 0.04 & 0.06 & 0.08 & 0.09 & 0.07 & 0.05 & 0.06 & 0.05 & 0.07 \\
\hline Gumbel & 0.09 & 0.06 & 0.05 & 0.05 & 0.08 & 0.10 & 0.11 & 0.09 & 0.07 & 0.10 & 0.08 & 0.09 \\
\hline Log gum. & 0.04 & 0.07 & 0.07 & 0.07 & 0.02 & 0.01 & 0.02 & 0.01 & 0.05 & 0.09 & 0.06 & 0.05 \\
\hline
\end{tabular}

Table 5: Values of extreme rainfall estimated by the best fitting functions compared with the observed values

\begin{tabular}{|l|l|l|l|l|l|l|l|l|}
\hline \multirow{2}{*}{$\begin{array}{l}50 \quad \text { years } \\
\text { Period }\end{array}$} & Return & 1-Daily -Daily & \multicolumn{3}{l|}{ 3-Daily } & \multicolumn{2}{l|}{ 4-Daily } \\
\cline { 2 - 9 } & Est & Obs & Est & Obs & Est & Obs & Est & Obs \\
\hline Kottigehara & $\begin{array}{l}855.8 \\
(\mathrm{~L}-\mathrm{G})\end{array}$ & 538.5 & $\begin{array}{l}1455.4 \\
(\mathrm{~L}-\mathrm{G})\end{array}$ & 1050.3 & $\begin{array}{l}1922.2 \\
(\mathrm{~L}-\mathrm{G})\end{array}$ & 1281.4 & $\begin{array}{l}2403.5 \\
(\mathrm{~L}-\mathrm{G})\end{array}$ & 1568.5 \\
\hline Agumbe & $\begin{array}{l}582.8 \\
(\mathrm{~L}-\mathrm{G})\end{array}$ & 562.2 & $\begin{array}{l}820.7 \\
(\mathrm{~L}-\mathrm{N})\end{array}$ & 777.1 & $\begin{array}{l}1102.0 \\
(\mathrm{~L}-\mathrm{N})\end{array}$ & 1088.4 & $\begin{array}{l}1318.3 \\
(\mathrm{~L}-\mathrm{N})\end{array}$ & 1232.7 \\
\hline Ponnampete & $\begin{array}{l}703.6 \\
(\mathrm{~L}-\mathrm{G})\end{array}$ & 523.0 & $\begin{array}{l}1319.5 \\
(\mathrm{~L}-\mathrm{G})\end{array}$ & 712.7 & $\begin{array}{l}1382.2 \\
(\mathrm{~L}-\mathrm{G})\end{array}$ & 944.6 & $\begin{array}{l}1531.6 \\
(\mathrm{~L}) \mathrm{G})\end{array}$ & 1102.3 \\
\hline
\end{tabular}

\begin{tabular}{|c|c|c|c|c|c|c|c|c|}
\hline \multirow{2}{*}{$\begin{array}{l}100 \text { years Return } \\
\text { Period }\end{array}$} & \multicolumn{2}{|l|}{ 1-Daily } & \multicolumn{2}{|l|}{ 2-Daily } & \multicolumn{2}{|l|}{ 3-Daily } & \multicolumn{2}{|l|}{ 4-Daily } \\
\hline & Est & Obs & Est & Obs & Est & Obs & Est & Obs \\
\hline Kottigehara & $\begin{array}{l}1103.3 \\
\text { (L-G) }\end{array}$ & 869.2 & $\begin{array}{l}1871.4 \\
(\mathrm{~L}-\mathrm{G})\end{array}$ & 1453.4 & $\begin{array}{l}2462.4 \\
\text { (L-G) }\end{array}$ & 1809.1 & $\begin{array}{l}3098.2 \\
\text { (L-G) }\end{array}$ & 2215.4 \\
\hline Agumbe & $\begin{array}{l}669.0 \\
(\mathrm{~L}-\mathrm{G})\end{array}$ & - & $\begin{array}{l}874.5 \\
(\mathrm{~L}-\mathrm{G})\end{array}$ & - & $\begin{array}{l}1176.4 \\
(\mathrm{~L}-\mathrm{N})\end{array}$ & - & $\begin{array}{l}1405.4 \\
(\mathrm{~L}-\mathrm{N})\end{array}$ & - \\
\hline Ponnampete & $\begin{array}{l}951.6 \\
(\mathrm{~L}-\mathrm{G})\end{array}$ & 643.6 & $\begin{array}{l}1495.0 \\
\text { (L-G) }\end{array}$ & 1036.6 & $\begin{array}{l}1858.2 \\
\text { (L-G) }\end{array}$ & 1308.6 & $\begin{array}{l}2043.0 \\
\text { (L-G) }\end{array}$ & 1417.6 \\
\hline
\end{tabular}




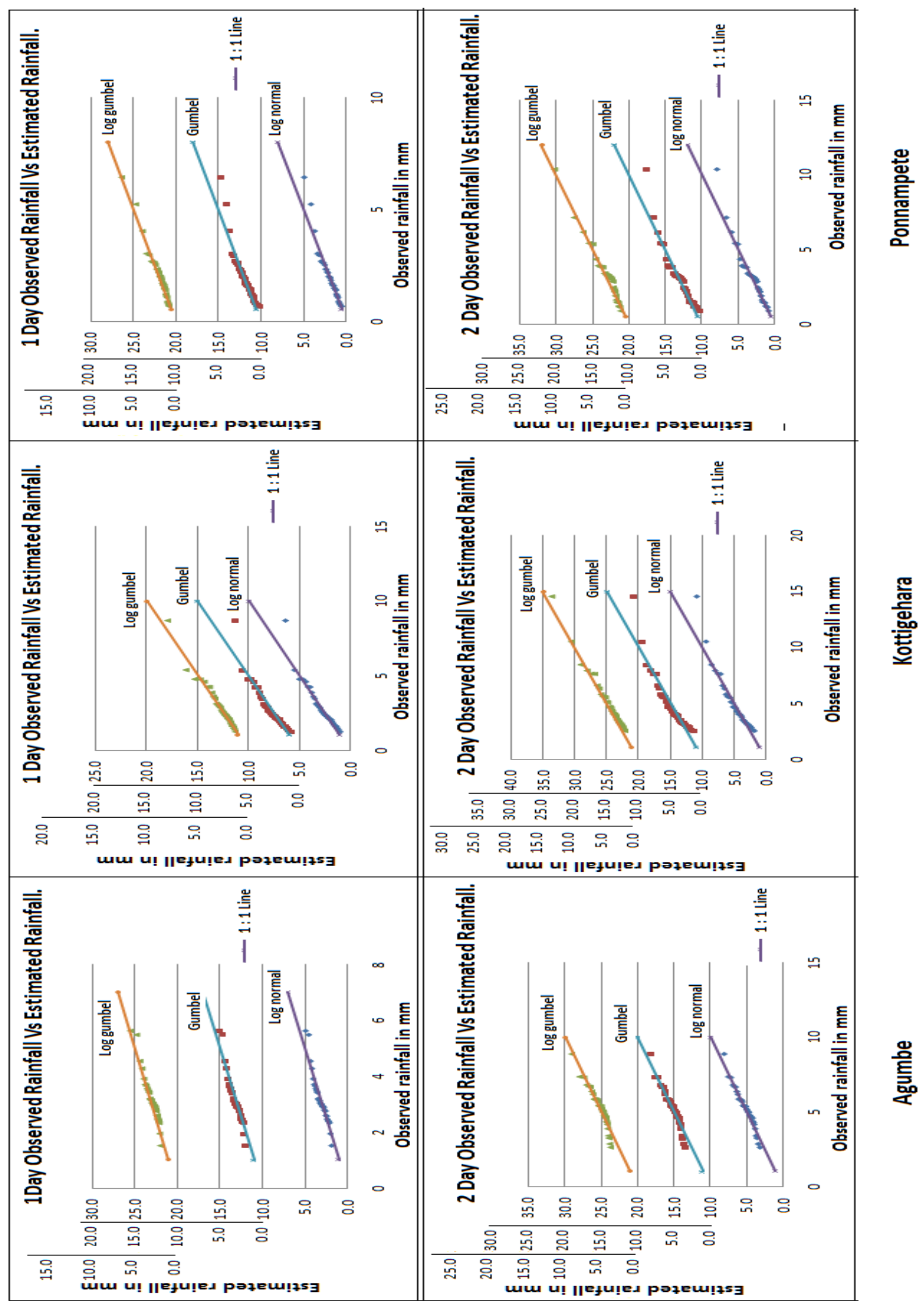

Fig 1: Scatter diagrams (sample) comparing rainfall estimated by probability functions with those observed. 